\title{
DiVERSIDADE SEXUAL E GÊNERO NA ESCOLA: UMA EXPERIÊNCIA DE EXTENSÃO NO RIO DE JANEIRO
}

\section{Gender and sexual diversity in schools: an experience of extension in Rio de Janeiro}

\section{Diversidad sexual y género en la escuela: una experiencia de extensión en Rio de Janeiro}

\author{
Luan Carpes Barros Cassal ${ }^{1}$ \\ Luciana Patrícia Zucco²
}

\begin{abstract}
RESUMO
Este artigo apresenta a análise dos relatos de professores da rede pública e privada de educação da região metropolitana do Rio de Janeiro sobre diversidade sexual e gênero na escola, a partir da experiência do projeto de extensão "Diversidade sexual na escola", da Universidade Federal do Rio de Janeiro. O método utilizado teve como base a pesquisa qualitativa e, como instrumento de coleta de dados, a observação das ações de extensão, no transcorrer de abril de 2007 a abril de 2008. Os dados foram registrados em diário de campo e codificados a partir da análise temática. Os núcleos de sentido identificados abarcam duas discussões: gênero, tendo como significado predominante a essencialização do feminino e do masculino; $e$ a representação do homossexual, contemplando as características simbólicas do homossexual e sua essencialização. Conclui-se que a escola produz discursos sobre a sexualidade sob a chancela do interdito e da norma, a partir do padrão heterossexual. A partir desse entendimento, os professores esperam dos alunos comportamentos sociais e sexuais adequados ao sexo biológico. Experiências que fujam dessa compreensão são denominadas "inadequadas" ou, ainda, "desviantes", como a bissexualidade e a travestilidade, não sendo, portanto, consideradas na realidade escolar. Nesse sentido, políticas públicas de formação inicial e continuada para a educação podem colaborar na construção e promoção de relações sociais mais igualitárias entre os sujeitos.
\end{abstract}

Palavras-chave: experiência de extensão; diversidade sexual; gênero; orientação sexual; escola.

\begin{abstract}
This article presents an analysis based on the experiences of teachers in both public and private education networks in the metropolitan region of Rio de Janeiro, about gender and sexual diversity in schools. The project started from the Extension Project "Sexual diversity in school", in Federal University of Rio de Janeiro. The method employed is based on quality research and observation. The data were collected during the planning and execution of the method's procedures, from April 2007 through April 2008, and registered in the procedure's diary and codified by thematic analysis. The identified meaningful core comprehends two debates: gender, having as its prevalent meaning the "essentialization" of feminine and masculine; and the representation of the homosexual, with its symbolic features and its "essentialization". It was concluded that schools produce discourses about sexuality under the token of interdiction and rules, based on the commonsense standards of heterosexuality. In this trend, the teachers expect the students to behave appropriately from social and sexual viewpoints, as is biologically imposed. Behaviors that go astray from this
\end{abstract}

\footnotetext{
${ }^{1}$ Mestrando do Programa de Pós Graduação em Psicologia pela Universidade Federal do Rio de Janeiro. Assistente de Coordenação do Projeto Diversidade Sexual na Escola da Universidade Federal do Rio de Janeiro. E-mail: luancassal@yahoo.com.br

2 Doutora em Ciências da Saúde pelo Instituto Fernandes Figueira/Fiocruz. Professora Adjunta da Escola de Serviço Social da Universidade Federal do Rio de Janeiro. Professora do Curso de Extensão Diversidade Sexual e Identidades de Gênero na Escola da Universidade Federal do Rio de Janeiro. Rua Bartolomeu Portela, 36, n. 202, Bairro Botafogo. Rio de Janeiro. CEP: 22.290-190. E-mail: lpzucco@uol.com.br
} 
conception are regarded as inadequate and even as unnatural; bissexuality and transvestism are seen as contrary to schools' reality. In this sense, public policies of early and continued formation and education come together for the construction and promotion of normal and equal social relationships.

Keywords: extension experience; sexual diversity; gender; sexual orientation; schools.

\section{RESUMEN}

A partir de la experiencia del Proyecto de Extensión "Diversidad Sexual en la Escuela", de la Universidad Federal de Rio de Janeiro, este artículo presenta un análisis de relatos de profesores del sistema público y privado de educación de la región metropolitana de Rio de Janeiro sobre diversidad sexual y género en la escuela. El método usado tuvo como base la investigación y observación cualitativos. Los datos fueran recogidos durante la planificación y ejecución de las acciones, entre abril de 2007 y abril de 2008, registrados en diario de campo, y codificados desde un análisis temático. Los núcleos de sentido identificados comprenden dos discusiones: género, teniendo como significado predominante la "esencialización" de lo femenino y de lo masculino; representación del homosexual, con sus características simbólicas y su "esencialización". Se concluye que la escuela produce discursos sobre sexualidad bajo el sello de lo entredicho y de la norma, desde un estándar heterosexual. Se sigue a eso que los profesores esperan de los alumnos comportamientos sociales y sexuales adecuados al sexo biológico; experiencias que no se encajen en esta comprensión son "inadecuadas" o "descarriadas", como la bisexualidad y el travestismo y, por ende, están fuera de la realidad escolar. En este sentido, políticas públicas de formación inicial y continuada para la educación pueden ayudar en la construcción y promoción de relaciones sociales más equitativas entre los sujetos.

Palabras-clave: experiencia de extensión; diversidad sexual; género; orientación sexual; escuela.

\section{Introdução}

No meu ensino fundamental, os professores ficaram boquiabertos que fui a única a tirar 10 no provão e na olimpíada de matemática. Alguns alunos até brincavam: "ah, é viado. Mas o viado tirou 10, quanto você tirou?" (Larissa)

Este artigo apresenta a análise dos relatos de professores da rede pública e privada de educação da região metropolitana do Rio de Janeiro sobre diversidade sexual e gênero na escola, a partir de uma experiência de extensão universitária. Todos os professores participaram de atividades do projeto de extensão intitulado "Diversidade sexual na escola"3, integrado ao Programa "Papo Cabeça", promovido pela Universidade Federal do Rio de Janeiro (UFRJ).
A extensão universitária é aqui compreendida como processo articulador do ensino e da pesquisa às demandas postas pela sociedade. Nesse sentido, a extensão passa a ser dimensionada como ação política, estratégia democratizante do conhecimento e metodologia voltada aos problemas sociais, capaz de assessorar e colaborar na organização dos novos movimentos sociais. Seu objetivo é, portanto, intervir na solução de problemas de relevância social e técnica para a sociedade. Tal definição é oriunda do Fórum de Pró-Reitores de Extensão em seu I Encontro Nacional, em 1987, sendo prevista na Constituição de 1988, em seu artigo 207, e reafirmada, em 1999, no Plano Nacional de Extensão.

Discutir a temática da diversidade sexual e identidade de gênero na ação extensionista justifica-se pelos alarmantes dados de casos de exclusão, violência e discriminação

\footnotetext{
${ }^{3}$ O projeto de extensão "Diversidade sexual na escola" é coordenado pelo comunicador social Alexandre Bortolini, e é financiado desde 2007 pela Secretaria de Educação Continuada, Alfabetização e Diversidade do Ministério da Educação (Secad/MEC), a partir do edital de Formação de Profissionais da Educação para a Promoção da Cultura de Reconhecimento da Diversidade Sexual e da Igualdade de Gênero, como cumprimento do programa "Brasil sem homofobia". Disponível em: <http://www.papocabeca.me.ufrj.br/diversidade>.
} 
sofridos por lésbicas, gays, bissexuais, travestis e transexuais (LGBT ${ }^{4}$ ). Carrara e Ramos (2004) identificaram que $58,5 \%$ da população LGBT do Rio de Janeiro entrevistada na Parada do Orgulho de 2003 sofreu discriminação por conta de sua orientação sexual. Estes casos de violência foram pouco notificados às autoridades, pois apenas $8,8 \%$ entraram em contato com a polícia, e um número ainda menor acionou outras instituições, como, por exemplo, as organizações de direitos humanos. Mott, Cerqueira e Almeida (2007) apontaram, ainda, que 132 homossexuais foram assassinados por crimes de ódio em 2001, número este provavelmente subnotificado.

Para Abramovay, Castro e Silva (2004), a escola aparece em terceiro lugar como local ou contexto de discriminação por orientação sexual ( $27 \%$ dos casos) e mantém a mesma posição como espaço onde acontecem as agressões $e$ outras violências (10\%), atrás apenas do ambiente familiar e do grupo de amigos e vizinhos. Os autores indicam também que $15 \%$ dos estudantes e $16 \%$ dos educadores consideram a homossexualidade uma doença. Assim, a escola distancia-se da sua função social de educar e proteger e se apresenta como mais um espaço de relevante segregação social. Diante do apresentado, algumas indagações chamam a atenção: que concepções de feminino e masculino pautam as práticas profissionais dos educadores? Os discursos dos professores sobre diversidade sexual na escola estão ancorados nas concepções de gênero? Estas visões de mundo poderiam reproduzir formas de discriminação aos alunos supostamente LGBT?

Para explicitar as questões acima, primeiramente serão apresentados o caminho de investigação percorrido, a descrição dos dados construídos e, posteriormente, a discussão do material obtido à luz das categorias teóricas de gênero e de diversidade sexual. A análise colabo- ra para a compreensão de como a diversidade sexual e as relações de gênero são produzidas e reproduzidas no ambiente escolar a partir dos relatos profissionais dos educadores.

\section{Caminho metodológico}

Considerando que a fala dos professores se refere a elementos subjetivos da realidade e está em um nível que não pode ser quantificado, adotou-se como abordagem o estudo qualitativo (MINAYO, 1995) e, como instrumento de coleta de dados, a observação das ações extensionistas de formação de professores no ambiente escolar. Foote-Whyte (1990) oferece algumas pistas de como trabalhar a observação, sendo uma delas participar da realidade do grupo social de maneira imparcial, mas sempre de forma autêntica. Minayo (1995) soma a tais indicações alguns aspectos ao afirmar que "o observador, enquanto parte do contexto de observação, estabelece uma relação face a face com o observado. Nesse período ele, ao mesmo tempo, pode modificar e ser modificado pelo contato" (p. 59).

Ressalta-se que a configuração do corpus é um momento da análise e, de fato, a primeira imersão no trabalho de operacionalização. Neste são estabelecidos limites, recortes e um movimento constante que remete da teoria ao corpus e à análise e vice-versa, sendo, portanto, uma construção do próprio pesquisador. Destarte, os sujeitos da pesquisa foram professores do ensino fundamental e médio, e graduandos que participaram das atividades do projeto "Diversidade sexual na escola".

Nesse sentido, durante o período de abril de 2007 a abril de 2008 foram coletados

\footnotetext{
${ }^{4}$ O uso da sigla LGBT atende às recomendações da Associação Brasileira de Gays, Lésbicas, Bissexuais, Travestis e Transexuais (ABGLT) de dar maior visibilidade ao segmento de lésbicas no ativismo brasileiro e está em consonância com as tendências internacionais, ao projetar a atuação das lésbicas na superação da ideologia patriarcal e de dominação masculina.
} 
dados por meio da participação no planejamento e nas ações desenvolvidas. Isso possibilitou a construção de um diário de campo com relatos oriundos de aproximadamente 35 encontros, nos quais foram discutidos os temas de diversidade sexual, gênero e orientação sexual nas escolas, e suas implicações para a prática educacional. Cabe destacar que os registros não tinham roteiro preestabelecido, embora as categorias teóricas anteriormente mencionadas servissem de referência para a escolha do que se constituiria como dado de análise. Outro instrumento utilizado foi gravação em fita $\mathrm{K} 7$, apenas em algumas atividades, que também serviram como fonte de registro.

Para a construção dos dados, primeiramente realizou-se uma leitura flutuante do material e, em seguida, foram selecionados os relatos que traziam casos sobre a temática em discussão. No segundo momento, fez-se o trabalho de codificação a partir das categorias previamente selecionadas e daquelas advindas com o empírico (relatos) para, então, identificar os núcleos de sentidos.

De acordo com Minayo (1995, p. 70), o trabalho de classificação de categorias: "significa agrupar elementos, idéias ou expressões em torno de um conceito". Ao final, as interpretações foram realizadas à luz da discussão teórica, o que possibilitou responder às questões surgidas com a observação participante e apontar novas indagações. Ressalta-se, também, que as falas utilizadas no estudo não apresentam identificação dos sujeitos, sendo fictícios todos os nomes citados.

\section{Resultados}

A construção dos dados permitiu identificar na fala dos professores dois núcleos temáticos centrais, com seus sentidos. Estes foram assim organizados: o primeiro núcleo temático se refere ao gênero, tendo como sentido predominante a essencialização do feminino $e$ do masculino; o segundo, a representação do homossexual, com identificação de dois sentidos: as características simbólicas do homossexual e sua essencialização. Tais resultados podem ser compreendidos como diferentes dimensões do fenômeno social, indicando, além do contexto, o lugar que os professores ocupam e suas produções subjetivas ${ }^{5}$.

\subsection{Gênero: a essencialização do feminino e do masculino}

Os relatos dos professores demonstram conflitos em relação às compreensões de feminino e masculino que estão à margem das normas de gênero. Essas representações são igualmente associadas a uma orientação sexual não convencional. Cabe destacar que o fato de os alunos destoarem da norma faz com que sejam marcados por suas características transgressoras.

Uma aluna batia nos meninos, brigava com os meninos, todo mundo pensava que era lésbica e, de repente, ela apareceu grávida, e depois disse que não, nunca gostou de mulheres. (professora 1 )

\footnotetext{
${ }^{5}$ A subjetividade é aqui referenciada segundo o pensamento de Guattari (1996), que a define como construção de sujeitos - masculinos e femininos - em relação, atravessados, dentre outros elementos, pela história e pela sociedade, o que acaba por produzir efeitos na maneira como os sujeitos se relacionam entre si e consigo mesmos. Nessa perspectiva, pode-se entender que os encontros entre profissionais e alunos contribuem para a produção de subjetividades.
} 
Uma vez chamei um aluno, conversei, ele falou que queria ser homem, engrossou a voz, conversei com a turma que não queria mais problema. No ano seguinte, veio todo feminino... (professora 2)

Uma aluna fazendo uma bagunça, perturbando, perturbando, perturbando, aí chegou uma hora em que não aguentei mais e fiz assim "porque para com isso, que saco, vê se isso fica bem, uma menina agindo dessa forma!". E aí a turma virou e falou assim: "professor, é um menino"... (professor 3)

Tal entendimento implica uma construção que coloca a orientação homossexual feminina como negação da possibilidade do sujeito de exercitar as ditas características do gênero feminino. Uma compreensão similar ocorre com a orientação homossexual masculina, que destitui o sujeito da sua condição de homem. Assim, a lesbianidade e o gay ocupam o lugar no imaginário daquele que não produz continuidade de existência, segundo uma visão essencialista e biologizante.

$\mathrm{Na}$ visão dos professores, os alunos precisam ser (re)normatizados à sociedade. Os discursos, portanto, demonstram a estreita determinação do sexo biológico para a construção do gênero e, consequentemente, da prática sexual. Identifica-se, desse modo, a reprodução de uma lógica unilateral que cerceia as subjetividades, sendo ela própria uma construção da sociedade moderna.

Segundo diferentes estudos (HITA, 2002; HEILBORN, 1999; LOURO, 2007; 1996; LOYOLA, 1999; 1998; SIMÕES; FACCHINI, 2009), os sujeitos passam a organizar seus modos de existência e relações tanto a partir das dimensões que envolvem sexualidade, sexo $e$ gênero, como de suas representações. Esse con- junto de elementos atravessa as relações instituídas em sociedade, com destaque à concepção de gênero, que interfere na forma como sexualidade e sexo são experimentados pelos sujeitos.

Na cultura ocidental, cobra-se uma forma bastante fixa de ser homem e de ser mulher, como polos opostos e excludentes (LOURO, 1996), e modelo legítimo. A mulher é construída como aquilo que não é o homem, com características voltadas ao cuidado e ao mundo privado; por sua vez, os predicados masculinos privilegiam a provisão e a vivência do espaço público. Destoar da imagem do masculino, dominante, e do feminino, dominado, ao se apresentar de outras formas é, em alguma medida, uma ofensa ao reconhecido socialmente como "normal".

Além disso, as representações de gênero são tomadas como valores que se espraiam pelas instituições sociais, sendo a escola um dos espaços de formação, de produção de subjetividades e de institucionalização das normas (FOUCAULT, 1999). No caso da adoção das noções do feminino e do masculino pelos professores, identificam-se sentidos em seus discursos que remetem a uma compreensão naturalizada do gênero. Cabe destacar que a compreensão binária de gênero e de prática sexual não é heteronormativa ${ }^{6}$ por acaso. Segundo Foucault (1999), ela possibilitou a produção de corpos, de sexualidades e de uma organização social, a partir do disciplinamento $e$ da manutenção das relações sociais e de poder instituídas.

\subsection{A representação do homossexual}

Este núcleo temático agrega discussões de gênero e de orientação sexual que não são tomadas como padrões pela sociedade, mas que são produzidas no interior dela e referenciam subjetividades. Analogamente à discussão de gênero, em que feminino e masculino são construídos em oposição nas relações, também as

\footnotetext{
${ }^{6}$ Esse termo é utilizado para designar que as relações afetivas e sexuais ocorrem entre sexos diferentes, ou seja, a norma tem como referência a orientação heterossexual. De modo geral, na sociedade ocidental é partilhada uma imagem de que todas as pessoas são heterossexuais até que algo declare o contrário, o que coloca outras orientações sexuais e identidades de gênero como periféricas ao padrão.
} 
orientações sexuais "periféricas" se constituem em referência e oposição às orientações heterossexuais. Desse modo, ao se tratar de orientação heterossexual, está-se, de alguma forma, dialogando com os demais modos de existência e de desejo sexual. Cabe ainda destacar que, nos discursos dos professores, ao tratar da diversidade sexual, dois sentidos foram preponderantes sobre a representação do homossexual: as características simbólicas e um entendimento ancorado numa leitura essencialista. Tais sentidos estão intrinsecamente articulados e referenciados pelas concepções de gênero.

Características simbólicas da homossexualidade

Este núcleo de sentido versa sobre determinada estética e modo de expressão esperados dos homossexuais, segundo as falas dos professores. Aponta, portanto, para três considerações.

A primeira abarca os discursos que remetem a uma aparência homossexual compartilhada socialmente. Recorrendo à mitologia grega, pode-se entender que a representação do gay estaria associada à transição de Ares, deus da guerra, símbolo de força e masculinidade, representado pelo escudo e pela lança, para Afrodite, deusa do amor e da beleza, representada, por sua vez, por um espelho. Nesse sentido, permanece a ideia do homossexual identificada por Fry e MacRae (1993), na década de 1990, qual seja: a do gay como subvertendo a condição masculina e migrando para uma identificação feminina.

A segunda consideração trata da ênfase dada pelos professores à homossexualidade masculina em detrimento da feminina. Isso leva a pensar o quão paradigmática é a figura do masculino na sociedade, e como é temida sua retirada do lugar de referência nas relações sociais. Para Uziel (2002), a expressão masculina de sexualidade é o modelo hegemônico de nossa sociedade e, portanto, é a norma pela qual as mulheres, e quaisquer outras expressões de gênero, são julgadas.
Ademais, a autora diz que as práticas excludentes são invisíveis para aqueles que estão dentro do padrão hegemônico, sendo notadas apenas pelos excluídos, quando não podem ter acesso a direitos. Por outro lado, a transgressão feminina da sexualidade talvez não se dê em relação à orientação homossexual, mas à vivência do desejo corporal e sexual. Fry e MacRae (1993) apontam que o maior desvio do feminino seria a exacerbação do prazer, tomada representativamente pela prostituição.

Como última consideração deste núcleo de sentido, tem-se a indissociabilidade entre sexo, gênero e orientação sexual. Essa associação pode gerar confusão sobre o conteúdo de cada termo, bem como produzir tensões como a citada abaixo.

Trabalhei numa escola em que era proibido usar brinco. Eu entrei e usava brinco, os alunos vieram quase chorando porque eu podia e eles não, porque a diretora disse que era coisa de viado. Falei com a diretora e ela disse que eu podia porque já era formado. Perguntei que moral eu teria, os alunos me perguntariam se sou viado também, não é? (professor 17)

Tinha um menino afeminado, e nenhum aluno discriminava, era o xodozinho da turma... O professor da turma gritava mais alto que os outros pra ele: "ô homo, ô homo, senta aí homo sapiens". (professora 19)

Para além do espaço escolar, tal constatação foi apontada por Fry e MacRae (1993) e Kulick (2008) ao estudar a sociedade brasileira. Ou seja, a fala dos professores alude a apreensões coletivamente partilhadas sobre o que é o sexo biológico e como este determina a materialização social do feminino e do masculino, e de suas orientações sexuais. Desse modo, os sujeitos estão fadados às suas características genéticas e biológicas. Estas passam a direcionar os modos 
de ser e de viver o sexo, o gênero e a orientação sexual, explicitando uma visão essencialista da heterossexualidade, também presente na visão da homossexualidade.

\section{A essencialização do homossexual}

Assim como a construção do feminino e do masculino ganha historicamente um tom natural de essência, a representação da orientação sexual passa por processos similares, identificada nos corpos e em seus comportamentos. Destarte, as normas sociais ultrapassam a lógica heteronormativa, pois carregam em si prescrições para as identidades sexuais consideradas periféricas. Ou seja, há um modo, se não aceito, no mínimo naturalmente esperado de ser gay e lésbica.

A expressão da homossexualidade é popularmente referenciada por uma imagem do gay efeminado e da lésbica masculinizada, que não está distante das falas encontradas no corpus do estudo.

Eu tinha um aluno que nunca tinha se assumido, mas tinha trejeitos. Os colegas implicavam, ridicularizavam, $e$ ele reclamava. Eu conversei com ele e falei que ele não tem que dar satisfação da sua vida, você que sabe de si. Ele conseguiu se formar, encontrei ele hoje advogado e assumido. (professora 18)

Quando você trabalha com um aluno ao longo do ano, quando chega lá no terceiro bimestre, o menino senta mais com as meninas, fica de tititi, esse menino que tem indícios de homossexualismo e vai se tornar gay tem uma postura diferente, faz fila [de meninos] e fica olhando. (professor 26)

Os relatos citados são representativos dos demais coletados nas ações de extensão, e nenhum traz práticas sexuais homoeróticas. Centraram-se nas expressões de gênero presentes nos comportamentos dos alunos no ambiente escolar. Essas expressões eram entendidas como indicativos daquela orientação homossexual posta como algo constitutivo dos sujeitos.

A primeira citação descreve, conforme a professora, um aluno efeminado que não se assumiu, mas que dispunha de potencial para tanto. De modo similar, na segunda, o professor lista características compreendidas a priori como definidoras e comuns aos homossexuais. Esses relatos exemplificam a visão dos professores sobre a conduta dos alunos, e eles podem ser entendidos tal qual a figura de um iceberg. Ou seja, existe "algo" a mais nos comportamentos dos alunos que não é dito, mas está presente.

Logo, ter um determinado comportamento social significa ser homossexual, não pelo ato sexual em si, mas pelas representações a ele associadas. $\mathrm{O}$ relato de um dos professores exemplifica essa reflexão: "um [aluno] hetero passou a mão na bunda do outro, o diretor viu e quase expulsou os dois. Não importa ser ou não ser, importa parecer" (professora 6). Os dados trazem uma profusão de discursos que, concomitantemente, nomeiam e cristalizam os modos de ser homossexual como inerentes exclusivamente ao seu universo e a nenhum outro, e que estão estreitamente relacionados a características simbólicas.

\section{Considerações finais}

A escola, como as demais instituições, está inserida num contexto social referenciado por normas e valores coletivamente partilhados. Como espaço dedicado à formação e produção de cidadãos (BRASIL, 1998), ela tanto reproduz tais preceitos quanto pode ser responsável pela produção de mudanças culturais significativas. Essa dinâmica marca a fala dos professores ao tratarem das questões que envolvem a diversidade sexual e de gênero, embora a tendência de manutenção e de perpetuação tenha prevalecido sobre a possibilidade de alteração do instituído. 
Nos posicionamentos dos professores, as discussões de gênero, além de estar institucionalizadas, atravessam as múltiplas dimensões da vida de seus alunos. As falas são referenciadas pelo que historicamente se construiu como masculino e feminino, creditando como periféricas as expressões que não correspondem ao sexo biológico. Associadas a esse entendimento estão as orientações sexuais, igualmente designadas como periféricas.

Para Louro (1996), as categorias universais servem para legitimar aqueles que já estão legitimados, tornando os outros "invisíveis" e sem referências: "o reconhecimento de diversas categorias (classe, etnia, gênero, geração, orientação sexual, religião...) nos conduz, também, a perceber e a conceitualizar de outro modo as relações de poder" (p. 16). Há complexa rede de relações dominante/dominado que se constroem por essas inúmeras categorias, algumas de forma velada, talvez porque se dão na esfera do privado ou porque se tornaram habituais, por estarem introjetadas.

Os professores, por vezes, acreditam fazer o melhor por seus alunos, agindo "pedagogicamente", ao tentar adequar seus comportamentos "desviantes". Isso acaba por constituir um rol de alunos marcados, quando não excluídos ou evadidos do ambiente escolar. Paradoxalmente, quanto mais os professores lidam com a diversidade sexual na escola, mais ela é identificada e ganha visibilidade. A produção de discursos para renormatizar e eliminar a existência dos excluídos tem como efeito identificar novos excluídos. A existência da norma implica sujeitos que não se adaptam a ela, estabelecendo relações de poder permanentes em um processo que se autoalimenta. Destarte, o encontro da escola com a temática da diversidade sexual é inevitável e permanente.

Entretanto, a dificuldade reside na restrita compreensão da diversidade, assentada nas características anatômicas e fisiológicas, bem como na lógica binária de sexo. No depoi- mento dos professores, esse fato levou ao relato de situações homossexuais, mas à ausência de outras expressões e comportamentos sociais e sexuais, como a bissexualidade, a transexualidade e a travestilidade. Logo, a produção de discursos sobre as diferentes práticas sexuais $e$ seus sentidos é reproduzida, como se dá prevalentemente, sob a chancela do interdito, e, desse modo, reafirmam-se e intensificam-se as relações hierárquicas entre os gêneros na sociedade. $\mathrm{O}$ movimento de repressão da sexualidade impede falas, mas também produz subjetividades nas práticas, na organização institucional e como critério de separação dos sujeitos.

Ademais, na escola, a sexualidade aparece com destaque por causa das resistências em se lidar com o tema, pelo fato de serem adolescentes, e porque algumas famílias se mostram contrárias ao debate. Como, então, tornar a escola um espaço de construção coletiva da cidadania? E, mais, de que forma transformar a escola pública em universal e laica, de fato?

Ações de formação podem colaborar nesse sentido. Os profissionais de educação se sentem despreparados para o encontro com tais temáticas. Dessa maneira, a inclusão de disciplinas como gênero e sexualidade na grade curricular e em cursos de pós-graduação se mostra fundamental, inclusive para a implantação do Tema Transversal da Orientação Sexual, previsto nos PCN (BRASIL, 1998), pois a formação e capacitação continuada dos professores pode ser um dos elementos que assegurem a mobilidade que a educação representa na vida dos sujeitos.

Os PCN preveem professores atentos ao mundo e capazes de absorver o que o mundo lhes traz, para exercer suas funções de problematizadores e orientadores. Soma-se a isso a necessidade de elaboração de materiais didáticos que contemplem as discussões de gênero e da diversidade sexual, além da ampliação destas na rede educacional pública e privada. Abordando de forma transversal tais temáticas, por meio de várias linguagens - artes, música, teatro, 
literatura, ciências exatas e biológicas, línguas - promove-se a construção de uma sociedade mais igualitária. Nessa perspectiva, a inclusão da orientação sexual nos currículos escolares possibilita trabalhar com os adolescentes as relações de gênero, o desenvolvimento do respeito a si e ao outro, bem como à diversidade de crenças, valores e expressões culturais existentes na sociedade.

\section{REFERÊNCIAS}

ABRAMOVAY, Miriam; CASTRO, Mary Garcia; SILVA, Lorena Bernadete da. Juventude e sexualidade. Brasília: Unesco Brasil, 2004. 426 p.

BRASIL. Parâmetros curriculares nacionais: terceiro e quarto ciclos do ensino fundamental. Temas transversais. Brasília, DF: Ministério da Educação/ Secretaria de Ensino Fundamental, 1998. 42 p.

CARRARA, S.; RAMOS, S. Política, direitos \& sexualidade (Parada Gay Rio de Janeiro 2003). Boletim Segurança e Cidadania. Ano 2, n. 1. Rio de Janeiro: Cesec-Ucam, 2004. p 1-16.

FOOTE-WHYTE, William. Treinando a observação participante. In: GUIMARÃES, Alba Zaluar (Org.). Desvendando máscaras sociais. Rio de Janeiro: Francisco Alves, 1990. p. 77-86.

FOUCAULT, Michel. História da sexualidade I: A vontade de saber. 13. ed. São Paulo: Graal, 1999. 152 p.

FRY, Peter; MAC RAE, Edward. O que é homossexualidade. São Paulo: Brasiliense, 1993. 125 p.

GUATTARI, Felix. Micropolítica - Cartografias do desejo. Petrópolis: Vozes, 1996.

HEILBORN, Maria Luiza (Org.). Construção de si, gênero e sexualidade. In: _. Sexualidade: o olhar das Ciências Sociais. Rio de Janeiro: Jorge Zahar, 1999. p. 40-58.

HITA, Maria Gabriela. Igualdade, identidade e diferença(s): Feminismo na reinvenção de sujeitos. In: ALMEIDA, Heloisa Buarque de; COSTA, Rosely Gomes; RAMÍREZ, Martha Celia; SOUZA, Érica Renata de (Orgs.). Gênero em matizes. Bragança Paulista: Coleção Estudos CDAPH, 2002. p. 319-352.

KULICK, Don. Travesti: prostituição, sexo, gênero e cultura no Brasil. Rio de Janeiro: Fiocruz, 2008. 279 p.

LOURO, Guacira Lopes (Org.). O corpo educado: pedagogia da sexualidade. Belo Horizonte: Autêntica, 2007. $176 \mathrm{p}$.

Extensão em Foco, Curitiba, n. 5, p. 15-23, jan.jun. 2010. Editora UFPR
. Nas redes do conceito de gênero. In: LOPES, Marta Julia Marques; MEYER, Dagmar Estermann; WALDOW, Vera Regina (Orgs.). Gênero e saúde. Porto Alegre: Artes Médicas, 1996. p. 7-18.

LOYOLA, Maria Andréa. A sexualidade como objeto de estudo das ciências humanas. In: HEILBORN, Maria Luiza (Org.). Sexualidade: o olhar das Ciências Sociais. Rio de Janeiro: Jorge Zahar, 1999. p. 31-39.

(Org.). Sexo e sexualidade na antropologia. In: . A sexualidade nas ciências humanas. Rio de Janeiro: UERJ, 1998. p. 17-47.

MINAYO, Maria Cecília de Souza (Org.). Pesquisa social: teoria, método e criatividade. 4. ed. Petrópolis: Vozes, 1995. $80 \mathrm{p}$.

MOTT, L.; CERQUEIRA, M.; ALMEIDA, C. O crime antihomossexual no Brasil. Disponível em: < http://www.ggb org.br/crime.html>. Acesso em: 09/12/2007.

SIMÕES, Júlio Assis; FACCHINI, Regina. Do movimento homossexual ao LGBT. São Paulo: Fundação Perseu Abramo, 2009. 196 p.

UZIEL, Anna Paula. Da intenção ao direito. Homossexualidade e adoção no Brasil. In: ALMEIDA, Heloisa Buarque de; COSTA, Rosely Gomes; RAMÍREZ, Martha Celia; SOUZA, Érica Renata de (Orgs.). Gênero em matizes. Bragança Paulista: Coleção Estudos CDAPH, 2002. p. 153-176.

Texto recebido em 13 de novembro de 2009

Texto aprovado em 15 de janeiro de 2010 